\title{
Predictive value of plasma copeptin level for diagnosis and mortality of pulmonary embolism
}

\author{
(iD) Caglar Ozmen ${ }^{1}$ \\ (D) Onur Sinan Deveci ${ }^{1}$ \\ (iD) Muhammet Bugra Karaaslan² \\ (iD) Oya Baydar \\ (iD) Anil Akray' \\ (iD)Ali Deniz ${ }^{1}$ \\ (D) Caglar Emre Cagliyan ${ }^{1}$ \\ (DI) Ismail Hanta ${ }^{3}$ \\ (iD) Ayhan Usal'
}

\begin{abstract}
1. Cukurova University, Faculty of Medicine, Department of Cardiology, Adana, Turkey. 2. Osmancik State Hospital, Department of Cardiology, Osmancık/Çorum, Turkey.
\end{abstract} 3. Cukurova University Faculty of Medicine, Department of Chest Disease, Adana, Turkey.

http://dx.doi.org/10.1590/1806-9282.66.12.1645

\section{SUMMARY}

OBJECTIVE: Early diagnosis and risk stratification may provide a better prognosis in pulmonary embolism (PE). Copeptin has emerged as a valuable predictive biomarker in various cardiovascular diseases. The aim of this study was to determine the levels of copeptin in patients with acute PE and to evaluate its relationship with disease severity and PE-related death.

METHODS: Fifty-four patients and 60 healthy individuals were included in this study. Copeptin concentrations and right ventricular dysfunction were analyzed. The correlation between copeptin levels and hemodynamic and echocardiographic parameters was examined. After these first measurements, patients were evaluated with PE-related mortality at the one-year follow-up.

RESULTS: The copeptin levels were higher in PE patients than in the control group ( $8.3 \mathrm{ng} / \mathrm{mL}$ vs $3.8 \mathrm{ng} / \mathrm{mL}, p<0.001)$. Copeptin levels were found to be significantly higher in patients with PE-related death and right ventricular dysfunction (10.2 vs $7.5 \mathrm{ng} / \mathrm{ml}, p=0.001$; 10.5 vs $7.5 \mathrm{ng} / \mathrm{ml}, p=0.002$, respectively). When the cut-off value of copeptin was $\geq 5.85$, its sensitivity and specificity for predicting $P E$ were $71.9 \%$ and $85.0 \%$, respectively ( $A \cup C=0.762,95 \% \mathrm{Cl}=0.635-0.889, p<0.001$ ).

CONCLUSIONS: The copeptin measurement had moderate sensitivity and specificity in predicting the diagnosis of PE, and the copeptin level was significantly higher in patients with PE-related death at the one-year follow-up. Copeptin may be a useful new biomarker in predicting diagnosis, risk stratification, and prognosis of PE.

KEYWORDS: Biomarkers. Death. Pulmonary embolism/diagnosis. Pulmonary embolism/mortality. Arginine vasopressin/metabolism.

\section{INTRODUCTION}

Acute pulmonary embolism (PE) is an obstructive disease of the pulmonary arterial system associated with significant mortality rates, i.e., up to $30 \%$, if not correctly diagnosed and treated'. Early diagnosis and risk stratification may provide better prognosis; however, there is not yet a particular biochemical

DATE OF SUBMISSION: 31-May-2020

DATE OF ACCEPTANCE: 08-Aug-2020

CORRESPONDING AUTHOR: Caglar Ozmen

Cukurova University, Faculty of Medicine, Department of Cardiology, Seyhan, Adana, Turkey - 01140

Tel: +90 532 583-9441

E-mail: caglarozm@hotmail.com 
marker useful for early diagnosis or for providing prognostic information. In clinical practice, scoring systems and some biomarkers with proven efficacy, such as D-Dimer, B-type natriuretic peptide (BNP) and troponin I, are used in the diagnosis and risk stratification of acute PE. Since D-Dimer levels may increase in many clinical conditions (cardiac arrest, trauma, hemorrhage, malignancies, shock, disseminated intravascular coagulation, and systemic inflammatory response syndrome), some difficulties arise in the diagnosis of $\mathrm{PE}^{2}$. The increase of BNP is highly sensitive but poorly specific for detecting PE patients at risk for severe adverse events, such as cardiac arrest, shock, need for intensive care units, need for thrombolysis, or vasopressors or mechanical ventilation ${ }^{3}$. It has been shown that troponin assays alone cannot be used to diagnose PE. Therefore, for clinicians, the heterogeneity of troponin assays and their lack of harmonization result in interpretative challenges ${ }^{4}$. Due to the many factors that can affect D-Dimer, BNP, and troponin levels in PE, results should be interpreted carefully.

Copeptin, the C-terminal part of pro-arginine vasopressin (AVP), is a glycosylated polypeptide consisting of 39 amino acids. Unlike AVP, copeptin is stable for a long time in plasma and is easily measured ${ }^{5,6}$. The clinical use of AVP is limited due to its particularly short half-life and its instability in frozen plasma ${ }^{7}$. In addition, more than $99 \%$ of circulating AVP is bound to platelets, and the small molecular size of AVP does not make it suitable for conventional immunoassays ${ }^{7}$. For these reasons, copeptin is now considered a well-defined surrogate biomarker for AVP. Due to its rapid release kinetics, copeptin has emerged as a valuable predictive and prognostic biomarker in several clinical conditions, including acute coronary syndrome, stroke, shock, and left heart failure ${ }^{8-11}$.

In acute PE, acute anatomical obstruction and vasoconstriction of the pulmonary artery (PA) result in increased pulmonary vascular resistance and right ventricular (RV) dilatation. At the same time, neurohumoral activation causes inotropic and chronotropic stimulation and, as a result, the AVP system is activated $^{12}$. Thus, copeptin may show a new pathophysiological axis of PE by reflecting a systemic reaction to impaired hemodynamics due to RV dysfunction in acute PE. Some studies have reported that copeptin may be a highly significant prognostic marker in early mortality and risk stratification in patients with acute $\mathrm{PE}^{13-15}$. In this study, we investigated the copeptin levels and their relationship with disease severity and PE-related death in acute PE.

\section{METHODS}

Study design

This single-center prospective study was performed in accordance with the ethical guidelines of the Declaration of Helsinki and was approved by the Medical Ethics Committee of the Cukurova University (Nr. 94). Written informed consent was obtained from all participants before enrollment. We included 54 patients diagnosed with acute PE who were referred to the Cukurova University Medical Faculty of Cardiology and Chest Disease Department (Adana, Turkey) between May 2018 and December 2018. The control group consisted of 60 healthy, age- and gender-matched volunteers who had no medical history, were on no medication, and came to the cardiology and chest disease outpatient clinic. When selecting the control group, careful attention was paid to ensure they were completely healthy volunteers. Candidates in the normal control group were excluded if they had a history of chronic diseases and their biochemical examination results, electrocardiogram, and echocardiography were abnormal. The exclusion criteria of the study population were as follows: acute or chronic inflammatory diseases, pulmonary hypertension (diagnosed by echocardiography), acute or chronic infectious diseases, history of venous thromboembolism, post-op or bed rest within the past 30 days, renal failure, and acute coronary syndromes. The severity of acute PE was defined according to the principles of the European Society of Cardiology (ESC) Guideline ${ }^{\mathrm{s16}}$. Acute PE patients were evaluated regarding PE-related death and RV dysfunction at the one-year follow-up. The patients' clinical statuses were evaluated with face-to-face assessments and telephone interviews during the follow-up.

The echocardiographic examination was performed using the Vivid S5 cardiovascular ultrasound system with a $3 \mathrm{~S} 1.5$ - 3.6 MHz transthoracic probe (GE Medical Systems, Buckinghamshire, UK) to evaluate RV dimensions and function. The assessment of RV size was performed by measuring RV end-diastolic mid-cavity diameters from the apical four-chamber view. Tricuspid annular plane systolic excursion (TAPSE) was measured as the displacement of the lateral tricuspid annulus toward the apex during the systolic movement of the RV. Individually, the RV dysfunction was 
evaluated for the presence or absence of the following signs: TAPSE $<15 \mathrm{~mm}$ and RV/LV end-diastolic ratio > 1 or mid-cavity RVEDD (right ventricular end-diastolic diameter) $>35 \mathrm{~mm}$ from the apical four-chamber view. If two or more of these criteria were present, RV dysfunction was diagnosed.

\section{Biochemical analyses}

Blood samples were collected from patients and the control group within a maximum of six hours after the diagnosis of acute PE to evaluate the acute phase. Plasma BNP levels were analyzed using an immunoassay kit (Biosite Diagnostics, La Jolla, CA). The measurable range of the BNP assays was 5.0 to $5000.0 \mathrm{pg} /$ $\mathrm{mL}$. Plasma D-dimer levels were assessed using the Liatest D-Di immuno-turbidimetric assay (Diagnostica Stago), with $\geq 0.5 \mu \mathrm{g} / \mathrm{mL}$ as the cut-off value. Copeptin was measured using a commercially available ELISA kit (EASTBIOPHARM, Hangzhou Eastbiopharm Co. Ltd., China) with a detection limit of $0.024 \mathrm{ng} / \mathrm{mL}$ and an inter-assay coefficient of $12 \%$. The tubes were immediately placed on ice and centrifuged at 2,000 $\mathrm{x}$ $\mathrm{g}$ for $15 \mathrm{~min}$ at $4^{\circ} \mathrm{C}$ to collect the plasma, which was divided into aliquots and stored frozen at $-80^{\circ} \mathrm{C}$ for further analyses.

\section{Statistical analysis}

Descriptive data were shown as $\mathrm{n}$ and \% values in categorical data and mean \pm standard deviation and median interquartile range values in continuous data. The chi-square test was used for the comparison of categorical data. The measurement data were tested for normal distribution by the Kolmogorov-Smirnov test. The Mann-Whitney U test and Kruskal-Wallis test were used, wherever appropriate, for the comparison of non-normally distributed measurement data. The Independent Samples t-test was used in independent groups for normally distributed data. Relationships between copeptin and baseline variables were assessed by Spearman rank correlation coefficients. The threshold value for copeptin in disease prediction was determined by the ROC curve analysis. $\mathrm{P}<0.05$ was considered statistically significant for all analyses. The analyses were performed using IBM৫ SPSS version 20.

\section{RESULTS}

The study was conducted with a total of 114 participants. Of the participants in the study, 54 (44.4\%) were in the patient group and $60(55.6 \%)$ were in the control group. The mean age of the patient group was $56.81 \pm 11.3$ years, and the mean age of the control group was $53.73 \pm 15.0$ years. Gender, age, and body mass index distributions were similar between the groups.

The distribution of the characteristics and clinical features of the patients is shown in Table 1. Intermediate-high risk $P E$ was diagnosed in 16 patients $(29.6 \%)$, intermediate-low risk in 23 (42.6\%), and low-risk in 15 (27.8\%). Twelve patients $(22.2 \%)$ were taking thrombolytic treatment, and $42(77.8 \%)$ patients were treated with heparin according to the current guideline ${ }^{17}$. Three patients (5.6\%) died during in-hospital or 30-day observation. PE-related death occurred in 12 patients $(22.2 \%)$ at the one-year follow-up.

TABLE 1. THE BASELINE CHARACTERISTICS, CLINICAL SYMPTOMS, AND COMORBIDITIES OF THE STUDY COHORT

\begin{tabular}{|c|c|c|c|}
\hline & & $n$ & $(\%)$ \\
\hline \multirow[t]{2}{*}{ Subjects } & Control & 60 & $(55.6)$ \\
\hline & Patient & 54 & $(44.4)$ \\
\hline \multirow[t]{4}{*}{ Symptoms } & Chest pain & 10 & $(18.5)$ \\
\hline & Dyspnea & 17 & $(31.5)$ \\
\hline & Syncope & 9 & $(16.7)$ \\
\hline & Signs/symptoms of DVT & 18 & $(33.3)$ \\
\hline \multirow[t]{4}{*}{ Risk factors for VTE } & Previous trauma/surgery & 12 & $(22.2)$ \\
\hline & Lower extremity DVT & 19 & $(35.2)$ \\
\hline & Travel/immobilisation & 10 & $(18.5)$ \\
\hline & Unprovoked & 13 & (24.1) \\
\hline \multirow[t]{3}{*}{ Risk Categories } & Low-risk & 15 & $(27.8)$ \\
\hline & Intermediate-low risk & 23 & $(42.6)$ \\
\hline & Intermediate-high risk & 16 & (29.6) \\
\hline \multirow[t]{5}{*}{ Comorbidities } & $\begin{array}{l}\text { Chronic compensated heart } \\
\text { failure }\end{array}$ & 14 & (25.9) \\
\hline & Chronic pulmonary disease & 11 & $(20.4)$ \\
\hline & Obesity & 11 & $(20.4)$ \\
\hline & Diabetes mellitus & 10 & $(18.5)$ \\
\hline & Anemia & 8 & $(14.8)$ \\
\hline \multirow{3}{*}{$\begin{array}{l}\text { Hemodynamic status } \\
\text { at presentation }\end{array}$} & Mild hypotension & 14 & (25.9) \\
\hline & Tachycardia & 24 & $(44.5)$ \\
\hline & Hypoxia & 16 & (29.6) \\
\hline PE-related death & & 12 & (22.2) \\
\hline Rv Dysfunction & & 13 & $(24.1)$ \\
\hline
\end{tabular}

DVT: deep vein thrombosis, RV: Right ventricle, VTE: Venous thromboembolism

The levels of troponin I (0.31 \pm 0.44 vs $0.16 \pm 0.22$ $\mathrm{ng} / \mathrm{mL} ; \mathrm{p}<0.014)$, BNP (524 \pm 361 vs $168 \pm 247 \mathrm{pg} / \mathrm{mL}$; $\mathrm{p}<0.001)$ and D-Dimer (4.125 $\pm 3.154 \mathrm{vs} 1.327 \pm 2.345 \mathrm{ng} /$ $\mathrm{mL} ; \mathrm{p}<0.001)$ were higher in acute PE patients compared to the control group. Copeptin was higher in PE patients than in the control group (8.3 vs $3.8 \mathrm{ng}$ / 
$\mathrm{mL} ; \mathrm{p}<0.001)$. In addition, copeptin was found to be significantly higher in patients with PE-related death and RV dysfunction at the one-year follow-up (10.2 vs $7.5 \mathrm{ng} / \mathrm{ml}, \mathrm{p}=0.001$ for PE-related death; 10.5 vs 7.5 $\mathrm{ng} / \mathrm{ml}, \mathrm{p}=0.002$ for RV dysfunction) (Table 2). When the cut-off value of copeptin was taken as $\geq 5.85$, its sensitivity and specificity for predicting PE were $71.9 \%$ and $85.0 \%$, respectively (AUC $=0.762,95 \% \mathrm{CI}=0.635$ $0.889, \mathrm{p}<0.001$ ) (Figure 1). Their negative and positive predictive values were $83.4 \%$ and $80.2 \%$, respectively.

TABLE 2. EXAMINATION OF COPEPTIN LEVELS ACCORDING TO DEMOGRAPHIC AND CLINICAL FEATURES

\begin{tabular}{|c|c|c|c|c|}
\hline & & \multicolumn{2}{|c|}{ Copeptin } & \multirow[t]{2}{*}{$p$} \\
\hline & & Median & $\begin{array}{l}\text { (Interquartile } \\
\text { Range) }\end{array}$ & \\
\hline \multirow{2}{*}{ Subjects } & Control & 3.8 & $(3.0-4.6)$ & \multirow{2}{*}{$<0.001$} \\
\hline & Patient & 8.3 & $(7.0-9.5)$ & \\
\hline \multirow{2}{*}{ Gender } & Female & 5.2 & $(4.3-8.2)$ & \multirow{2}{*}{0.304} \\
\hline & Male & 4.7 & $(3.3-7.5)$ & \\
\hline \multirow{3}{*}{$\begin{array}{l}\text { Risk } \\
\text { Categories }\end{array}$} & Low-risk & 6.1 & $(5.6-6.7)$ & \multirow{3}{*}{$<0.001$} \\
\hline & $\begin{array}{l}\text { Intermediate-low } \\
\text { risk }\end{array}$ & 8.3 & $(7.4-9.2)$ & \\
\hline & $\begin{array}{l}\text { Intermediate-high } \\
\text { risk }\end{array}$ & 10.5 & $(9.4-11.2)$ & \\
\hline \multirow{2}{*}{$\begin{array}{l}\text { PE-related } \\
\text { death }\end{array}$} & No & 7.5 & $(6.7-8.4)$ & \multirow{2}{*}{0.001} \\
\hline & Yes & 10.2 & $(9.5-11.9)$ & \\
\hline \multirow{2}{*}{$\begin{array}{l}\text { Rv } \\
\text { Dysfunction }\end{array}$} & No & 7.5 & $(6.8-8.8)$ & \multirow{2}{*}{0.002} \\
\hline & Yes & 10.5 & $(8.7-11.2)$ & \\
\hline
\end{tabular}

RV: Right ventricle

\section{FIGURE 1}

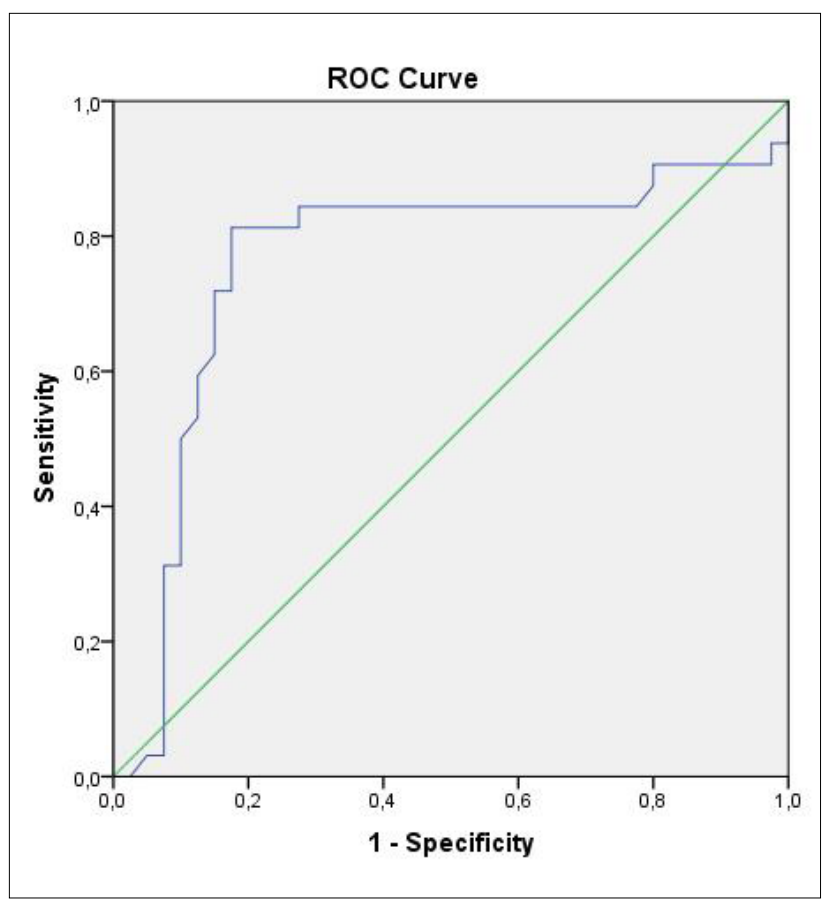

Copeptin levels showed a linear increase as the risk category increased according to post-hoc analysis results. Copeptin concentration in low-risk PE was $6.1 \mathrm{ng} / \mathrm{mL}$, in intermediate-low-risk PE it was $8.3 \mathrm{ng} /$ $\mathrm{mL}$, and in intermediate-high risk PE it was $10.5 \mathrm{ng} /$ $\mathrm{mL}(\mathrm{p}<0.001$ for each). Moderate and positive correlations were found between copeptin and pulse, RVEDD, and $\mathrm{RV} / \mathrm{LV}$ ratio $(\mathrm{r}=0.571, \mathrm{p}<0.001 ; \mathrm{r}=0.588, \mathrm{p}<0.001$; $\mathrm{r}=0.504, \mathrm{p}=0.003$, respectively). There were strong and positive correlations between copeptin and the respiratory rate $(\mathrm{r}=0.705, \mathrm{p}<0.001)$. There was a strong and negative correlation between copeptin and arterial oxygen saturation ( $\mathrm{r}=-0.726, \mathrm{p}<0.001)$, and a moderate and negative correlation between copeptin and TAPSE ( $\mathrm{r}=-0.461, \mathrm{p}=0.008$ ).

\section{DISCUSSION}

The main findings of this study are as follows: 1) The copeptin measurement had moderate sensitivity and specificity for predicting acute PE; 2) Copeptin was significantly higher in patients with PE-related death and in patients who developed acute RV failure at the one-year follow-up; 3) Copeptin levels increased as the risk class increased in patients with acute PE.

Copeptin is stoichiometrically secreted with AVP from the neurohypophysis and is more stable than AVP, thus overcoming the limitations and difficulties of AVP measurement ${ }^{6}$. Copeptin is released into the blood circulation in life-threatening stress conditions. These include heart failure ${ }^{11}$, acute coronary syndrome $^{8}$, sepsis ${ }^{18}$, pulmonary hypertension ${ }^{19}$, and acute $\mathrm{PE}^{13-15}$.

Copeptin appears to be particularly useful for the prognostic assessment of acute diseases due to its rapid release kinetics ${ }^{20}$. In their study, Kalkan et al. ${ }^{21}$ reported that the group including patients with acute PE had higher copeptin levels compared to those without acute PE. The cut-off value of copeptin was 4.84 $\mathrm{ng} / \mathrm{dL}$ for the diagnostic predictor of acute PE and had a sensitivity of $68.1 \%$ and specificity of $83.7 \%$ in this study. In our study, when the cut-off value of copeptin was $\geq 5.85 \mathrm{ng} / \mathrm{mL}$, its sensitivity and specificity were $71.9 \%$ and $85.0 \%$, respectively, for the diagnostic predictor of acute PE (AUC=0.762, 95\% CI=0.635-0.889, $\mathrm{p}<0.001)$.

Acute $\mathrm{PE}$ is associated with a high mortality rate. In their study, Hellenkamp et al. ${ }^{22}$ found a 7.6 -fold higher risk of PE-related death in the group with high copeptin levels. In our study, it was found that patients 
with PE-related death at the one-year follow-up had significantly higher levels of copeptin. Limited biomarkers have been identified in the diagnosis and risk stratification of $\mathrm{PE}$ and for predicting acute RV failure, which is the most common cause of death in acute $\mathrm{PE}^{14}$. Vasopressin is engaged in myocardial remodeling through its V1 receptor on cardiomyocytes, causing increased ventricular hypertrophy, decreased contractility, and the process of myocardial fibrosis ${ }^{23}$. Even though AVP is mainly derived from the $\mathrm{LV}$, these data increase the probability that elevated AVP levels in PE patients play a role in $\mathrm{RV}$ remodeling. In our study, copeptin was significantly higher in patients with PE in whom RV dysfunction developed. In addition, we found a significant positive correlation between copeptin and the RV/ $\mathrm{LV}$ ratio and RVEDD and a significant negative correlation between copeptin and TAPSE. The activation of the AVP system - calculated by copeptin levels - might be an early indication of neurohumoral stimulation in patients with RV dysfunction.

In this study, copeptin levels reflected PE severity. Risk assessment using the algorithm proposed by the 2019 ESC guideline requires three steps (assessment of hemodynamic stability, laboratory test/imaging methods, and calculation of the pulmonary embolism severity index score), resulting in a complicated and costly approach ${ }^{17}$. Wyzgał et al. ${ }^{14}$ reported a relationship between the severity of the disease and increased copeptin levels in PE. Hellenkamp et al. ${ }^{13}$ performed a study including 268 PE patients, and it was concluded that copeptin could be useful for risk stratification. For these reasons, there is an increasing need for rapid alternative biomarker-based strategies in predicting acute PE diagnosis and risk assessment. Our findings suggest that copeptin may be an essential marker in predicting the diagnosis and PE-related deaths.

We recognize some limitations of this study. It was a single-center study with a relatively small sample size. To eliminate the contributing effect of comorbidities on the deaths of patients with PE, the study had many exclusion criteria that limit the generalizability of our study.

\section{CONCLUSION}

Copeptin levels are elevated in patients with PE, and the measurement of copeptin concentration may help in predicting diagnosis, risk stratification, and prognosis of acute PE patients. Multicenter and more extensive studies are necessary to determine its role in predicting acute normotensive PE patients and confirm the prognostic value of copeptin.

\section{Conflict of interest statement}

All authors confirmed that there are no conflicts of interest associated with this publication.

\section{Ethics}

This study was performed in accordance with the ethical guidelines of the Declaration of Helsinki and approved by the Medical Ethics Committee of Cukurova University (Nr. 94).

\section{Author's Contribution}

The concept for research or article/hypothesis generation: Caglar Ozmen, Onur Sinan Deveci; Planning the methods to generate hypothesis: Anil Akray, Caglar Emre Cagliyan; Supervision and responsibility for the organization and course of the project and manuscript preparation: Ayhan Usal, Caglar Ozmen, Oya Baydar; Supplying equipment, space, and personnel vital to the Project: Onur Sinan Deveci, Ismail Hanta, Caglar Emre Cagliyan; Biological materials, reagents, referred patients: Ali Deniz, Oya Baydar, Muhammet Bugra Karaaslan; Discussion of the results, approval of the final version of the work: Muhammet Bugra Karaaslan, Onur Sinan Deveci, Ali Deniz. 


\section{RESUMO}

OBJETIVO: O diagnóstico precoce e a estratificação de risco podem proporcionar um melhor prognóstico em casos de embolia pulmonar (EP). A copeptina surgiu como um valioso biomarcador preditivo de várias doenças cardiovasculares. O objetivo deste estudo é determinar os níveis de copeptina em pacientes com EP aguda e avaliar a sua relação com a severidade da doença e mortes relacionadas à EP.

MÉTODOS: Um total de 54 pacientes e 60 indivíduos saudáveis foram incluídos neste estudo. As concentrações de copeptina e disfunções ventriculares direitas foram analisadas. A correlação entre os níveis de copeptina e parâmetros ecocardiográficos e hemodinâmicos foi examinada. Após essas primeiras medições, os pacientes foram avaliados em relação à mortalidade relacionada à EP após um ano.

RESULTADOS: Os níveis de copeptina foram maiores em pacientes com EP do que no grupo de controle $(8,3 \mathrm{ng} / \mathrm{mL} \mathrm{vs} 3,8 \mathrm{ng} / \mathrm{mL}$, $p<0,001)$. Os níveis de copeptina eram significativamente maiores em pacientes com mortes relacionadas à EP e disfunção ventricular direita (10,2 vs 7,5 ng/ml, $p=0,001 ; 10,5$ vs 7,5 ng/ml, $p=0,002$, respectivamente). Com um valor de corte $\geq 5,85$ para a copeptina, sua sensibilidade e especificidade preditivas para EP foram 71,9\% e 85,0\%, respectivamente (AUC=0,762, 95\% IC=0,635 - 0,889, p<0,001).

CONCLUSÃO: A medição da copeptina teve sensibilidade e especificidade preditivas moderadas para o diagnóstico de EP, e o nível de copeptina foi significativamente maior em pacientes com mortes relacionadas à EP após um ano. A copeptina pode ser um novo biomarcador preditivo útil para o diagnóstico, a estratificação de risco e o prognóstico de PE.

PALAVRAS-CHAVE: Biomarcadores. Morte. Embolia pulmonar/diagnóstico. Embolia pulmonar/mortalidade. Arginina vasopressina/ metabolism.

\section{REFERENCES}

1. Bĕlohlávek J, Dytrych V, Linhart A. Pulmonary embolism, part l: epidemiology, risk factors and risk stratification, pathophysiology, clinical presentation, diagnosis and nonthrombotic pulmonary embolism. Exp Clin Cardiol. 2013;18(2):129-38.

2. Hahne K, Lebiedz P, Breuckmann F. Impact of d-dimers on the differential diagnosis of acute chest pain: current aspects besides the widely known. Clin Med Insights Cardiol. 2014;8(Suppl. 2):1-4.

3. Masotti L, Righini M, Vuilleumier N, Antonelli F, Landini G, Cappelli R, et al. Prognostic stratification of acute pulmonary embolism: focus on clinical aspects, imaging, and biomarkers. Vasc Health Risk Manag. 2009;5(4):567-75.

4. Hogg K, Haslam S, Hinchliffe E, Sellar L, Lecky F, Cruickshank K. Does high-sensitivity troponin measurement aid in the diagnosis of pulmonary embolism? J Thromb Haemost. 2011;9(2):410-2.

5. Morgenthaler NG, Struck J, Alonso C, Bergmann A. Assay for the measurement of copeptin, a stable peptide derived from the precursor of vasopressin. Clin Chem. 2006;52(1):112-9.

6. Treschan TA, Peters |. The vasopressin system: physiology and clinical strategies. Anesthesiology. 2006;105(3):599-612.

7. Łukaszyk E, Małyszko J. Copeptin: pathophysiology and potential clinical impact. Adv Med Sci. 2015;60(2):335-41.

8. Lattuca B, Sy V, Nguyen LS, Bernard M, Zeitouni M, Overtchouk P, et al. Copeptin as a prognostic biomarker in acute myocardial infarction. Int J Cardiol. 2019;274:337-41.

9. Katan M, Nigro N, Fluri F, Schuetz P, Morgenthaler NG, Jax F, et al. Stress hormones predict cerebrovascular re-events after transient ischemic attacks. Neurology. 2011;76(6):563-6.

10. Morgenthaler NG, Müller B, Struck J, Bergmann A, Redl H, Christ-Crain M Copeptin, a stable peptide of the arginine vasopressin precursor, is elevated in hemorrhagic and septic shock. Shock. 2007;28(2):219-26.

11. Pozsonyi Z, Förhécz Z, Gombos T, Karádi I, Jánoskuti L, Prohászka Z, et al. Copeptin (C-terminal pro arginine-vasopressin) is an independent longterm prognostic marker in heart failure with reduced ejection fraction. Heart Lung Circ. 2015;24(4):359-67.

12. Lankhaar JW, Westerhof N, Faes T], Marques KM, Marcus JT, Postmus $P E$, et al. Quantification of right ventricular afterload in patients with and without pulmonary hypertension. Am J Physiol Heart Circ Physiol. 2006;291(4):H1731-7.
13. Hellenkamp K, Schwung |, Rossmann H, Kaeberich A, Wachter R, Hasenfuß $\mathrm{G}$, et al. Risk stratification of normotensive pulmonary embolism: prognostic impact of copeptin. Eur Respir J. 2015;46(6):1701-10.

14. Wyzgał A, Koć M, Pacho S, Bielecki M, Wawrzyniak R, Kostrubiec M, et al. Plasma copeptin for short term risk stratification in acute pulmonary embolism. J Thromb Thrombolysis. 2016;41(4):563-8.

15. Deveci F, Öner Ö, Telo S, Kırkıl G, Balin M, Kuluöztürk M, et al. Prognostic value of copeptin in patients with acute pulmonary thromboembolism. Clin Respir J. 2019;13(10):630-6.

16. Lang RM, Badano LP, Mor-Avi V, Afilalo J, Armstrong A, Ernande L, et al. Recommendations for cardiac chamber quantification by echocardiography in adults: an update from the American Society of Echocardiography and the European Association of Cardiovascular Imaging. I Am Soc Echocardiogr. 2015;28(1):1-39.e14

17. Konstantinides SV, Meyer G, Becattini C, Bueno H, Geersing G), Harjola VP, et al; ESC Scientific Document Group. 2019 ESC Guidelines for the diagnosis and management of acute pulmonary embolism developed in collaboration with the European Respiratory Society (ERS). Eur Heart J. 2020;41(4):543-603.

18. Jiang L, Feng B, Gao D, Zhang Y. Plasma concentrations of copeptin, C-reactive protein and procalcitonin are positively correlated with APACHE II scores in patients with sepsis. J Int Med Res. 2015;43(2):188-95.

19. Nickel NP, Lichtinghagen $\mathrm{R}$, Golpon $\mathrm{H}$, Olsson KM, Brand K, Welte T, et al. Circulating levels of copeptin predict outcome in patients with pulmonary arterial hypertension. Respir Res. 2013;14(1):130.

20. Enhörning S, Wang TJ, Nilsson PM, Almgren P, Hedblad B, Berglund $G$, et al. Plasma copeptin and the risk of diabetes mellitus. Circulation. 2010;121(19):2102-8.

21. Kalkan AK, Ozturk D, Erturk M, Kalkan ME, Cakmak HA, Oner E, et al. The diagnostic value of serum copeptin levels in an acute pulmonary embolism. Cardiol J. 2016;23(1):42-50.

22. Hellenkamp K, Pruszczyk $P$, Jiménez D, Wyzgał $A$, Barrios D, Ciurzyński M, et al. Prognostic impact of copeptin in pulmonary embolism: a multicentre validation study. Eur Respir J. 2018;51(4):1702037.

23. Benedict CR, Johnstone DE, Weiner DH, Bourassa MG, Bittner $V$, Kay $R$, et al. Relation of neurohumoral activation to clinical variables and degree of ventricular dysfunction: a report from the Registry of Studies of Left Ventricular Dysfunction. SOLVD Investigators. J Am Coll Cardiol. 1994:23(6):1410-20. 